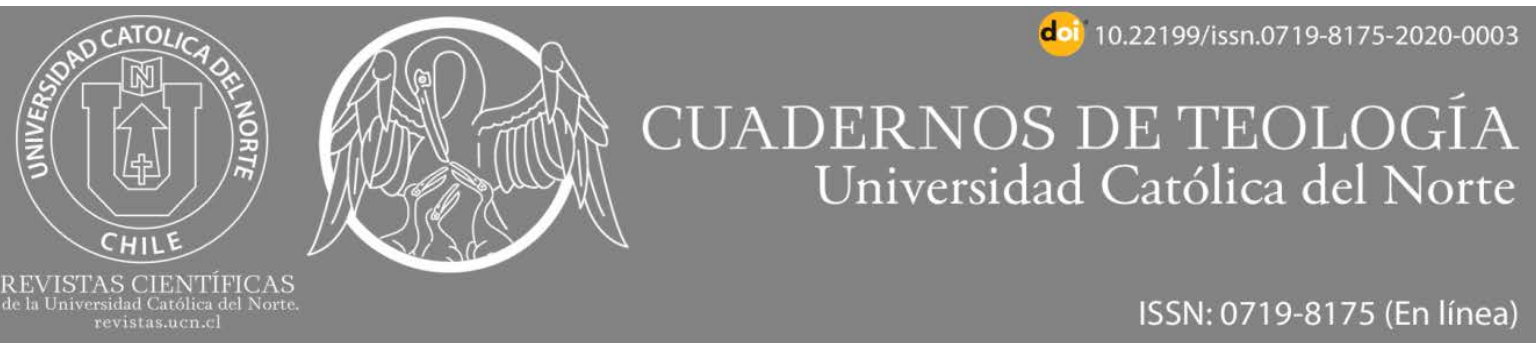

\title{
Virgen, monarquía y predicador en Patrocinio de María Santísima de Juan Millán de Poblete
}

\section{Virgin, Monarchy and Preacher in Patrocinio de María Santísima by Juan Millán de Poblete}

Leonor Taiano Campoverde ${ }^{1}$ (D) orcid.org/0000-0002-5634-9020

${ }^{1}$ University of Notre Dame du Lac. Doctoral candidate in the Hispanic Studies Program, Notre Dame, IN, USA. PhD. in Humanities and Social Sciences, Universitetet i Tromsø ,Norway.

(taianoc@nd.edu

$(\mathrm{cc}) \mathrm{BY}$

\section{Resumen:}

Se presenta un análisis panorámico del contenido textual y paratextual de Patrocinio de María Santísima, sermón escrito y predicado por Juan Millán de Poblete en la ciudad de México en 1693. Para hacerlo, se adopta una metodología filológica. El estudio parte de la premisa de que este texto constituye un excelente ejemplar de la homilética producida en Nueva España a finales del siglo XVII. La investigación presta especial atención al papel de la mariología al interior del texto y la manera cómo esta es combinada con motivos que realzan la importancia de la monarquía española, de sus autoridades y de sus súbditos. El texto resalta la supuesta misión salvífica de España, nuevo pueblo elegido por Dios, para divulgar el evangelio. Finalmente, se profundiza sobre theotokos, la función mediadora de María entre Dios y los hombres, su papel de auxiliadora de los cristianos y la relación del texto con la teología imperial.

Palabras Clave: Mariología; Theotokos; Homilética novohispana.

\section{Abstract:}

An analytical overview of the textual and paratextual elements of Patrocinio de María Santísima is presented, this sermon was written and preached by Juan Millan de Poblete in the city of Mexico in 1693. Therefore, this research adopts a Philological approach. The study starts from the premise that this text constitutes an example of the homiletics produced in New Spain at the end of the seventeenth century. This research pays particular attention to the role that Mariology plays within the text and how this Mariology is combined with motifs that enhance the importance of the Spanish monarchy, the Spanish authorities and the subjects of the Spanish King. The text highlights the supposed saving mission of Spaniards, new God's chosen people, to spread the gospel. Lastly, this paper dives on the theotokos, Mary's function of mediator between God and the human family, her role of helper of the Christians and her connection to the imperial theology.

Keywords: Mariology; Theotokos; Novohispanic homiletics. 
En la devoción que en todos mis Reinos se tiene a la Virgen Santísima, y en particular con que yo acudo en mis necesidades a implorar su auxilio, cabe mi confianza de que en los aprietos mayores ha de ser nuestro amparo y defensa; y en demostración de mi afecto y devoción, he resuelto que en todos mis Reinos se reciba por Patrona y Protectora, señalando un día, el que pareciere, para que en todas las ciudades, villas y lugares de ellos se hagan novenarios, habiendo todos los días Misas solemnes con sermones, de manera que sea con toda festividad, y asistiendo mis Virreyes y gobernadores y Ministros, por lo menos un día, haciéndose procesiones generales en todas partes, con las imágenes de mayor devoción de los lugares, para que con gran solemnidad y conmoción del pueblo se celebre esta fiesta (citado por Campos y Fernández de Sevilla, 2012, p. 708).

\section{Introducción}

La cita inicial corresponde a la cédula real en la que, en el año 1656, Felipe IV instituye, gracias a la aprobación de Alejandro VII, la fiesta del Patrocinio de Nuestra Señora, la cual debía celebrarse en un domingo de noviembre. He aludido a esta cédula real porque este estudio analiza un sermón cuyo contenido se relaciona con esta orden del rey habsbúrguico, me refiero a Patrocinio de María Santísima (1693) de Juan Millán de Poblete. El texto, poco estudiado hasta el momento, fue creado para ser pronunciado en la ya mencionada fiesta religiosa, en la cual se presentaba a María como abogada especial de la monarquía, basándose en su aparición a Santiago de Compostela en Zamora, la cual como bien indican los estudios de Fernando Negredo del Cerro—sellaba una triple alianza entre la virgen, Santiago de Compostela y la monarquía universal española (Negredo del Cerro, 2002, p. 303) ${ }^{1}$.

Este estudio aborda Patrocinio de María Santísima partiendo de la idea que la obra adhiere a la literatura legitimista de la época, en la cual la trilogía Dios-Virgen-Santiago conforma el eje protector de un proyecto político que hacía del monarca católico el vicario de Dios en la tierra. La investigación parte de la perspectiva que, tratándose de un texto del seiscientos europeo, siglo marcado por el barroco, el sermón está regido por silogismos escolásticos, (que no debe confundirse con el aristotélico, que toma como punto de partida el principio de que el conocimiento humano es inferior y subordinado a las verdades divinas. Cerbo, 2018, p. 82), que introducen lo dogmático en las diferentes esferas de la cotidianidad (De Fiores, 2005, pp. 243-246). El texto contiene temas comunes de la contrarreforma: la veneración a Inmaculada concepción, la función mediadora de María entre Dios y los hombres, su papel de auxiliadora de los cristianos (García-Saúco Beléndez, 1986, p. 34). Es decir, presenta una mariología relacionada con la teología y la política. Por consiguiente, el sermón se caracteriza por un fuerte simbolismo que entrelaza la protección mariana, la imagen del monarca español como alguien que va "plus ultra" debido a su fe, la promoción de España como el nuevo pueblo elegido por Dios y la trascendencia que el

\footnotetext{
${ }^{1}$ Visto que el objetivo de este artículo es dar a conocer el contenido de esta obra poco conocida, no realizaré un análisis comparativo de este, sino que me centralizaré en su estructura propiamente dicha. Sin embargo, me gustaría precisar que la obra posee muchas características en común con otras obras impresas a lo largo del siglo XVII. Por consiguiente, se puede afirmar que adhiere a los cánones de la mariología de la época.
} 
kerigma divulgado por los españoles tiene en la propagación de la fe. Tanto en los elementos textuales como paratextuales se señala que María protege a España porque en esta monarquía no solo se fusionan el interés civil y el divino, sino que también se demuestra que la causa pública depende de las autoridades y de los ciudadanos particulares, de los seculares y los religiosos. Es así como, desde el frontispicio hasta el colofón, la obra trata de demostrar que en la monarquía hispánica existe una jerarquía que va del elemento divino (María) al individuo común que aporta con su patrimonio para publicar una obra que defiende al status quo.

Tomando en cuenta lo anterior, esta investigación está dividida en tres partes. En la primera se analizan los elementos paratextuales. En la segunda se estudia la salutación del sermón, considerándola una antesala temática a la homilía propiamente dicha. En la tercera se examina la manera cómo Millán de Poblete entrelaza el theotokos de María, su patrocinio particular a España, la imagen positiva de los gobernantes españoles y la importancia de la figura del predicador. En consecuencia, mi estudio tratará de responder a las siguientes preguntas: ¿Cómo la mariología se asocia con la ideología imperial?, ¿Qué papel desempeña el predicador en la obra?, ¿Cómo describe Millán de Poblete a los monarcas españoles?, ¿Qué papel desempeña el virrey y el virreinato?

\section{Paratexto}

Es evidente que el texto del sermón propiamente dicho ha servido como modelador del paratexto. Es por ello que es importante examinar algunos aspectos del frontispicio, la dedicatoria y los pareceres, pues ofrecen una suerte de nomenclatura que permite entender más profundamente la concepción y organización de Patrocinio de María Santísima.

\subsection{Frontispicio}

El frontispicio, por ejemplo, ya deja entrever contenidos y matices de particular importancia. El título celebra el patrocinio mariano "discurrido" expresamente para la monarquía católica, la cual se construía principalmente gracias a la plataforma religiosa. Esta última la convertía en el aparato rector y protector del cristianismo (Martínez Millán, 2015, p. 217). En efecto, de manera sucinta, la portada monopoliza símbolos y personalidades que legitiman el poder español en Nueva España, sugiriendo que la relación de patrocinio entre la iglesia católica (representado por María) y la monarquía hispánica (formada por la corona, la iglesia y los súbditos) es proporcional y de recíproca correspondencia, pues es España quien defiende el cristianismo con todas sus fuerzas y es María quien les protege milagrosamente, permitiendo la expansión territorial española.

\section{Patrocinio \\ De María Santísima \\ Discurrido}

Propio y especial para la Católica Monarquía Española, en

Día de la fiesta de este título. En la Santa Iglesia Catedral Metropolitana de México

Presente 
El excelentísimo señor conde de Galve, virrey de esta

Nueva España. Con los señores de su Real Audiencia

$Y$

El ilustrísimo señor doctor D. Francisco de Aguiar y Seixas

Arzobispo de esta Santa Iglesia, del Consejo de su Majestad, y

Su muy ilustre y doctísimo cabildo, y la muy noble,

$Y$ muy Leal e Imperial Ciudad de México

EN EL SERMÓN

Que predicó y dedica a dicho señor excelentísimo, el doctor

D. JUAN MILLAN DE POBLETE, cura propietario, que

fue de dicha Santa Iglesia, hoy prebendado de ella. El día ocho

de Noviembre de 1693. Dominica 26. Postpentecostem

quinta que superfluit post epiph

A expensas del Br. Andrés Ortíz de Cobarrubias, Primodel Autor

CON LICENCIA EN MEXICO

Por los Herederos de la Viuda de Bernardo Calderón, Año de 1693

Como símbolos del poder tenemos la mención de la urbe y de un edificio muy importante: la catedral. La ciudad representa la encarnación física de los ideales de la corona, la reificación de los valores que afianzaron las estructuras imperiales y virreinales, pues-como bien señala Stephanie Merrim-los modelos clásicos de la ciudad como cúspide de la civilización avanzaron el ambiente urbano del siglo XVII (Merrim, 2012, p. 109). "La ideal e imperial ciudad de México" es corazón del proyecto de expansión español en Nueva España, en ella se materializa y teatraliza la ideología de la monarquía hispánica. La catedral representa a la iglesia madre, es fuente del sacerdocio y del oficio episcopal, en la cual se predica el evangelio (munus docendi), se administran los sacramentos (munus santificandi) y donde se pone en relieve la potestad de jurisdicción eclesiástica (munus regendi) (Zuanazzi, 2018, pp. 79-99). En cuanto a las personalidades, estas se articulan perfectamente con el poder civil de la urbe y con el poder eclesiástico: el virrey, los miembros de la real audiencia, el arzobispo (honorables testigos de la predicación) y el prebendado (autor del sermón). El virrey y los miembros de la real audiencia representan a la máxima autoridad terrenal en el virreinato. El arzobispo y el prebendado encarnan el poder divino y muestran que la influencia espiritual no era menor que el poder terrenal. Adicionalmente, se menciona a quien ha financiado la obra, el bachiller Andrés Rodríguez Cobarrubias, dejando en claro que este libro no proviene de las arcas reales, sino de la generosa contribución de un ciudadano local del virreinato. Finalmente, se especifica que el libro vio la luz en la imprenta de la viuda de Calderón y que este consta de licencia, pero no lleva privilegio.

\subsection{Dedicatoria}

Si bien es un ciudadano local es el fautor del sermón, la dedicatoria a Gaspar de la Cerda da a entender que la obra ha sido llevada a la imprenta por pedido de este virrey, a quien agradece su patrocinio, el cual — según el contexto- no parece remitir al aspecto económico, sino al apoyo y favorecimiento para que el contenido del sermón sea 
considerado relevante. Si en el frontispicio el conde de Galve forma parte de un conjunto de autoridades que simbolizan a España, en la dedicatoria se convierte en un abierto instrumento de apoyo a la impresión de Patrocinio de María Santísima. Millán de Poblete menciona que, por derecho, este sermón merece ser dedicado al virrey y a su cetro. No es casual que el prebendado novohispano haya decidido incorporar en la representación escrita del virrey un objeto que constituye una de las más espléndidas insignias monárquicas: el cetro. El cual, en las tradiciones judeo-heleno-cristiana, constituye simultáneamente un símbolo del poder soberano y del sacerdocio (Úzquiza Ruiz, 2012, pp. $18,37,40,77,167)$, es decir que, tanto desde el punto de vista monárquico como religioso, es un distintivo que alude al hecho de que el poder de determinado individuo posee respaldo divino. Millán de Poblete recuerda que el gobierno del conde de Galve está caracterizado por proezas y virtudes cuya grandeza es indescriptible.

Esta es [señor excelentísimo] una insinuación sola del derecho que hay para que este sermón se vaya a vuestra merced como a su cetro. No es manifestar en tan cortos periodos las proezas de vuestra excelencia, pues por mucho que se dilatara la pluma, nunca se alcanzará la más fecunda elocuencia a llenar el espacioso campo, en que las glorias de Vuestra Excelencia se dilatan, razón que tengo también para entregarme al silencio [...] manifestando por último que estas prerrogativas y las de benignidad, clemencia y afabilidad de vuestra excelencia son suaves coyundas con que sin violencia nos lleva vuestra excelencia a su amor [...] Motivo también para poner mi sermón debajo del patrocinio de vuestra excelencia, aunque tema mi cortedad el ir donde me impele la inclinación con que vivo afectuoso siempre a vuestra excelencia y con que pido a nuestro señor los felices progresos de su gobierno que gocemos por muchos años et siglos. México y Noviembre 20 de 1693 años. (1693, dedicatoria, s/n)

Aunque es evidente el carácter encomiástico del texto, este no se limita solamente a las adulaciones. A lo largo de la dedicatoria se puede notar que Millán de Poblete adopta un doble comportamiento hacia el conde de Galve: por una parte, presenta respeto y sumisión hacia este. Por otra, le recuerda la importancia que los sacerdotes tienen y siempre han tenido para influir en el poder y el orden de los territorios. Dicho de otra manera, Juan Millán de Poblete destaca que el poder político y el poder religioso van de la mano. Esto lo demuestra de manera progresiva. En primer lugar, recuerda que su sermón ha sido llevado a la imprenta por petición del virrey. Posteriormente alude a su temor de entregarlo a la censura y recuerda la importancia que, desde la Edad Media, varios sacerdotes han tenido en las cuestiones geopolíticas. Finalmente, alude a la magnitud que las gestas de los españoles han tenido en la propagación del catolicismo. El sacerdote novohispano establece analogías entre su demora al entregar el manuscrito a la imprenta y la aprensión experimentada por San Bernardo cuando tuvo que entregar su sermón sobre el "Cantar de los Cantares" a Bernardo de Portis. Asimismo, recuerda que tanto este patriarca como San Enodio y San Filoteo escribieron para complacer a una autoridad. Efectivamente, la alusión a estos autores se debe no solo al temor que ellos tenían de mostrar sus obras a los gobernantes que las requerían, sino al hecho de que su escritura fue crucial en momentos históricos decisivos. San Bernardo, por ejemplo, además de ser conocido por su devoción a la virgen, fue predicador de la segunda cruzada y sus sermones fueron celebrados tanto en 
el ámbito religioso como en el civil (Pastori Ramos, 2010, p. 72). En efecto, gracias a su prestigio la orden cisterciense pudo oponerse abiertamente al cisma provocado por el antipapa Anacleto II. Bernardo se movilizó para defender al que fue declarado verdadero sumo pontífice: Inocencio II (Olivera, 2018, pp. 144-163). En cuanto a San Enodio, su Panegyricus Theodorico Regi Dictus, es una obra de carácter histórico-panegírico-moral que promociona las virtudes del rey godo Teodorico. El texto alude a la conquista de Sirmio, a la victoria sobre Sabiniano y sobre los búlgaros. Enodio magnifica a Teodorico no solo por su valentía sino porque sabe apreciar aquellas acciones de los súbditos que reforzaron su poder (Arnold, 2014, pp. 57-80). De esta manera, el sacerdote novohispano reivindica la importancia de los buenos oradores para promocionar las virtudes de un regente, poniendo en relieve la importancia del panegirista. También alude al monje Filoteo de Kokkinos, cuya carta a Basilio III está a la base de las tesis sobre la monarquía universal moscovita. Según este monje, Moscú era la tercera Roma y sus monarcas debían garantizar la continuidad entre el imperio romano y el gran principado moscovita (Jiménez Sureda, 2014, pp. 87-128). De forma análoga a este sacerdote-profeta de la translatio imperii moscovita, Millán de Poblete expone que su función como predicador es profesar que la verdadera translatio corresponde a la monarquía española. El novohispano sustenta esta idea basándose en tesis providencialistas y en una visión teocrática de gobierno, vinculando el poder de la monarquía hispánica con los influjos del patrocinio mariano. Esto lo demuestra por medio de los casos de las conquistas llevadas a cabo por Cristóbal Colón y Hernán Cortés, quienes se encomendaron a María antes y durante sus epopeyas.

Pues si en él es el argumento de probar el especial derecho que tiene la católica monarquía a gozar, pues si se notó que fueron especialísimos influjos del particular patrocinio de María Santísima con la Católica monarquía el que saliere Don Cristóbal Colón al descubrimiento de este Nuevo Mundo víspera de Nuestra señora de las Nieves, y que pisase la primera isla que está entre la Florida, y Cuba, llamada Guanahani víspera de la señora del Pilar, y que el invicto Cortés, que le siguió en la derrota, le siguiese también en los auspicios, saliendo de España víspera de Nuestra Señora y llegando Víspera de la Santísima Virgen a la Vera-Cruz, y en su víspera cantó el Te deum laudamus en México por la victoria alcanzada, y fenecida, el día antes 13 de agosto y colmando los triunfos con decirse el día siguiente que fue de la Asunción la primera misa en esta santa iglesia. (1693, dedicatoria, s/n)

Adicionalmente, el sacerdote destaca que, al igual que Colón y Cortés, Gaspar de la Cerda elige días consagrados a la virgen para llevar a cabo sus proyectos. La devoción mariana de Gaspar de la Cerda tiene una dimensión político-ceremonial. María es la reina de las victorias y aciertos del conde de Galve. En otras palabras, en este sermón se inserta al gobierno de Gaspar de la Cerda dentro de una mariología política que lo legitima. Ella es la soberana de su virreinato:

Si tuvieron digo, siempre las católicas armas sus felices auspicios de los mismos días en que principiaban o ejecutaban sus proezas por ser dedicados a María Santísima. Qué otra cosa hemos visto en vuestra excelencia sino elegir siempre días consagrados a María Santísima para sus proyectos, señalando los sábados para sus entradas y aciertos, siendo en todo tan cordial la devoción de vuestra excelencia a 
esta divina señora como todos experimentamos con no poda edificación nuestra y ejemplo de los demás.(1693, dedicatoria, $\mathrm{s} / \mathrm{n}$ )

El culto y devoción de Gaspar de la Cerda a la virgen proviene de su linaje pío. En efecto, después de encomiar la devoción mariana del virrey, el autor alude a las peregrinaciones que sus ascendientes hicieron a tierra santa y establece un continuum entre la fe del conde y la de estos y, por analogía, entre la fe de los nobles españoles del pasado y los del presente. Una retórica similar se encontrará en el sermón propiamente dicho, en el cual se alude a la grandeza de los reyes de España debido a que estos tienen la fe en María y la fuerza de su linaje, ya que son — según los mitos fundacionales de la monarquíadescendientes de Hércules.

\subsection{Pareceres}

El deseo que el sermón de Millán del Poblete tiene en resaltar que la devoción mariana española ha permitido que los españoles se convirtiesen en el nuevo pueblo elegido no pasa desapercibido por Francisco de Florencia, quien afirma:

El predicador discurre muy alto en todo, puedo decir que el Patrocinio común a toda la iglesia lo ha hecho tan particular de España, que parece que esta fiesta se hizo solo para mostrar el cariño (digámoslo así) con que la virgen santísima se ha mostrado patrona muy especial y muy singular de los reinos de España. (1693, parecer de Francisco de Florencia, $\mathrm{s} / \mathrm{n}$ )

En su parecer, el jesuita aprueba el contenido del libro y el deseo de llevar a cabo una geo-politización de la religión por medio del culto mariano y del favoritismo que la virgen tiene hacia los españoles. Ambos elementos se convierten en el símbolo de la monarquía universal española y del sometimiento de esta a las directivas eclesiásticas. Dicho de otra manera, es obvio que el censor percibe el texto como una reafirmación de que la monarquía hispánica poseía toques divinos.

Díganlo los favores con que se ha mostrado de su parte desde aquel especial que hizo al glorioso patrón de España, el apóstol Santiago, viniendo la señora en persona desde Jerusalén a España a templar sus congojas, y siendo así, que aún no había ido al Empireo (que conste, ni de la escritura, ni de historia auténtica) Vino a España primero, favor, que parece hizo al rey español, con quien se ha mostrado más favorable. (1693, parecer de Francisco de Florencia, s/n)

De hecho, tanto Francisco de Florencia como Joseph de Olivares, el segundo censor, alaban las dotes de buen predicador de Juan Millán de Poblete. Del contenido de los pareceres se colige que para ellos Patrocinio de María Santísima refuerza el discurso regalista. Florencia considera que el sermón debe imprimirse para ser conocido, pues la prédica del novohispano posee un valor excepcional (opinión que no fue suficiente para que Patrocinio de María Santísima obtuviera el privilegio). Por consiguiente, eleva el texto a la categoría de obras cuyo contenido merece ir más de los límites del virreinato, ya que realza los símbolos y personajes relacionados con la tradición y fundamentos de la monarquía hispánica: 
Todo esto lo ha discurrido en este sermón Dr. D. Juan Millán, mejor que yo lo sabré ponderar, y así puede vuestra excelencia dar licencia para que se imprima, para que con eso, lo que dijo a vista de vuestra excelencia, se extienda a todos los reinos de Nueva España y aún a los de Europa, para que por medio de vuestra excelencia, conozcan en ellos lo que el orador merece por sus talentos, en especial por el del púlpito, vuestra excelencia será servido de hacer lo que más conviene [...]. En este colegio Máximo de San Pedro y San Pablo de México a 28 de noviembre de 1693 años. (1693, parecer de Francisco de Florencia, s/n)

Joseph de Olivares, por su parte, usa una imagen elocuente para poner a la luz las dotes retóricas y técnicas escriturales de Millán de Poblete. El segundo censor fusiona el sentido etimológico de la palabra texto - es decir tramar o entrelazar un tejido- con las tres túnicas más importantes de la tradición judío-cristiana: la túnica inconsútil de Jesús (véase el estudio de Fernando Milán, 2010), la túnica polímita que Jacob regaló a José (véase el estudio de André Wénin, 2011) y el talar de Arón (véase Joel Turpo Chaparro, 2014). Para Olivares Patrocinio de María Santísima es una túnica inconsútil bordada por Juan Millán de Poblete. Al mismo tiempo es una túnica polímita pues proviene del terliz de tres hilos marianos. El primero es de oro y representa el origen inmaculado de María. El segundo de plata y simboliza su virginidad, el tercero es púrpura real y encarna el patrocinio mariano a la corona española.

Si no me patrocinara la túnica inconsútil en que el orador bordó artificioso el patrocinio ecuménico de MARÍA, tejido y entretejido con el terliz hermoso de tres hilos: briscados de oro purísimo, resplandeciente esplendor de su origen inmaculado. Plata Virgen de su virginal entereza. Púrpura Real del materno patrocinio, conque socorre a España. Túnica polímita, por la variedad de gallarda erudición que la adorna, que dejó en sombras los primores de Jacob, en la peregrina de Joseph y en bosquejo la talar celeste de Aarón, aunque campeaba con el Mapa del Universo, en dibujos, guarnecida de tantas majestades, cuantas coronas le granaban la cimbria, aplaudida de tantas voces, cuantas crisóstomas lenguas le repicaban la falda. $Y$ así diré verosímil de la tela subida y trama recamada del sermón [...] Este sutil sermón proporcionalmente hablando; todo, del todo es de arriba, soberano, don de Dios, como la inconsútil túnica de que se vistió el señor. (1693, parecer de Olivera, s/n)

El censor hace del sacerdote novohispano alguien que ayuda — por medio de su texto o tejido- a perpetuar el patrocinio mariano. Por medio de Patrocinio de María Santísima, este sacerdote entrelaza la mariología con la historia y expansión de España. Millán de Poblete trenza las tramas simbólicas que configuran la naturaleza e identidad de la monarquía española. Él ha sabido captar diferentes mitos fundadores y eventos históricos para construir su sermón.

\section{Salutación}

A pesar de que los elementos paratextuales antes mencionados anticipan claramente el sentido de Patrocinio de María, es a partir de la salutación que Millán de Poblete comienza a hacer una serie de alusiones que abiertamente forman parte del círculo 
discursivo del sermón. De hecho, el autor anticipa los motivos que tratará en la marcha de su homilía y manifiesta su mariología política de manera muy eficiente por medio de la combinación del contenido ideológico-político-religioso con el sentido estético. En primer lugar, Millán de Poblete retoma la imagen del águila bicéfala, animal emblemático usado por los Austrias para recordar el patronato universal español (Guerrero Cano, 1983, p. 65). La reina de las aves encarna en este texto las cualidades políticas, morales y cristianas relacionadas con la supremacía. Este volátil con dos cabezas figura originalmente la unión de dos imperios y, en el caso de la monarquía universal hispánica, le permite simbolizar sus diversos territorios europeos y ultramarinos ${ }^{2}$ (De la Torre García, 2000). El punto de partida de la iconografía del águila bicéfala por parte de los Austrias remonta al año 1508, cuando Maximiliano I la incorporó a su escudo. Once años después, este se introduce en la península ibérica en un grabado de Carlos V, junto con el lema "plus ultra» (al que alude tanto en la salutación como en el sermón propiamente dicho) ya que Carlos V asumió como premisa de su reinado «ir más allá» de los límites establecidos, es decir, de las columnas levantadas por Hércules (Parker, 2001) 3. Para Millán de Poblete, el águila es la virtud guerrera y religiosa, un rapaz que le permite elaborar su discurso de exaltación ya que enlaza directamente el trono de los Habsburgo a la gloria divina. De hecho, después de mencionar al ave, refiere a la representación de María como estrella y enfatiza su función como fuente de esperanza y guía para los cristianos. María es un cuerpo celeste que desde las alturas puede ver todo, es legisladora y redentora de los españoles:

Estas no son dos estrellas, sino una con dos nombres. A la mañana Lucero, y Véspero o Héspero a la tarde. Supongo que por estos fines de la tierra se entiende España, a quien juzgaban los antiguos, que por ser lo último de la Europa, lo era también de la tierra toda, a quien servía de cinta, término o raya el Mar Atlántico, [...]. Y de aquí vino el poner Hércules las columnas con el non plus ultra. [...] De esta estrella se llamó España Hesperia dice San Isidoro [... . Y esta estrella es MARÍA Santísima, a cuyos influjos, a cuyo patrocinio vive amparada, y a quien siempre veneró la nación española con particulares cultos, aún en las sombras del gentilismo, no solo de la ancianidad, sino también de la infancia [...], pues los niños españoles refiere Amiano Marcelino, que después de puesto el sol encendían unas antorchas para recibirla y festejarla cuando saliere y al rayar sus luces clamaban: ánimo a las empresas, pues vemos la estrella, cuya tutela nos asegura las victorias [...] porque el vencer la infidelidad y el desarraigar al herejía no es cosa que se promete España de futuro, sino que lo da por hecho de presente con los rayos y patrocinio de esta su estrella. (Millán del Poblete, 1693, 1 v.)

Adicionalmente, como puede notarse en el fragmento arriba citado, Millán de Poblete retoma las tesis de Isidoro de Sevilla sobre el origen del término Hispania, derivado

\footnotetext{
${ }^{2}$ El águila bicéfala fue adoptada como emblema imperial por Constantino y se convirtió en la insignia del imperio romano de oriente hasta la última dinastía de emperadores bizantinos. Posteriormente fue usado por la dinastía Arsacida, por los zares de Rusia, por los reyes de Serbia, por los príncipes de Montenegro y por los Augsburgo. En el caso específico de estos últimos, les permitía representar que su majestad era de carácter sacro, nacida para continuar con la misión asignada a Constantino y Carlos Magno.

3 "Plus ultra" es el lema latino utilizado por Carlos V que desafía y deriva de las expresiones «Non plus ultra» y de «Nec plus ultra» usados en la época romana, basados en la mitología helénica, para indicar que Hércules había puesto dos pilares en el Estrecho de Gibraltar que indicaban el límite del Mundo. Era el «Non Terrae Plus Ultra» o Finisterre. Felipe II altera el lema de su padre tras la conquista de Portugal, a "Non sufficit orbis".
} 
de Hesperia, que a su vez ser relaciona con las voces Véspero o Héspero (Bengoechea, 1985, p. 257) y las fusiona con la tradición bíblica para construir la imagen de una monarquía que, aunque formada de varios reinos, es indivisible e indisoluble. De esta manera la salutación alienta el proyecto político-expansionista del "imperio en el que nunca se pone el sol" por medio de una suerte de ideario profético legitimador del proyecto imperial. En efecto, al concepto de la translatio imperii se suma un fuerte sentimiento mesiánico que introduce la idea de una monarquía guiada por Héspero- María, quien protege a España, el nuevo pueblo elegido, para que pueda vencer la infidelidad y la herejía. Conjuntamente, el novohispano retoma la creencia de la venida y aparición de la virgen María al apóstol Santiago sobre el pilar de Zaragoza. El sacerdote vincula la tradición mariana-pilarista con la jacobea para recordar los ejes fundamentales en torno a los cuales ha girado la espiritualidad patriótica española durante siglos:

Pues adviértase que esta estrella es movible, pues por la mañana nace y precede al sol y se llama lucero del alba, y a la tarde sigue al sol y se llama Héspero, conque ya está antes, ya después, y así movible luego ¿no es seguro su patrocinio? Antes sí que esta no es instabilidad de la Estrella, sino velocidad en socorrernos [...] ¿No es esta María Santísima que antes de venir Cristo, señor nuestro, y de nacer por boca de sus predicadores en España anunciaba los rayos y resplandores del sol? [...] ¿no le quedó a España esta estrella para desterrar las tinieblas de la idolatría, eligiendo al apóstol Santiago, su sobrino, para su enseñanza y cuidando María Santísima con tanta especialidad por la fe de España? ¿No le quedó también para la noche de sus tribulaciones? Sí, pues ven hay que su movilidad es presteza, y es como no limitarse a tiempo, ni ahora, pues a mañana y tarde, de día y de noche, asiste velocísima a nuestro amparo, franqueando sus propiedades a quien, cómo y cuándo, quiere. (Millán del Poblete, 1693, 2 r.)

Con estos motivos, la salutación nos ha anticipado el contenido central y primordial del sermón. En efecto, como veremos a continuación, Patrocinio de María Santísima se desarrolla en torno a cuatro puntos: el patrocinio de universal y particular de la virgen, la imagen del buen monarca, la propagación del evangelio y la importancia del predicador.

\section{Patrocinio de María: del theotokos a la predicación}

En coherencia con lo anterior, es en el sermón propiamente dicho donde Millán de Poblete amplia los elementos temáticos que dominan en los elementos paratextuales que le preceden y donde realiza su labor hermenéutica estrictamente hablando. El prebendado trata — como bien anunció Francisco de Florencia - de responder a la pregunta: "pues [si] es tan de todos el patrocinio de María Santísima ¿cómo se lo apropia y adjudica por tan suyo y especial la católica monarquía con este tan reverente culto?" (1693, 3 r.) Para hacerlo, el sacerdote novohispano desarrolla su respuesta en varias etapas que podrían dividirse de la siguiente manera: la primera es la del theotokos al patrocinio particular, la segunda va de los límites impuestos por las columnas de Hércules a la expansión que inicia gracias al pilar de María y, finalmente, las revelaciones y predicaciones que confirman el papel de España como nuevo pueblo elegido. 


\subsection{Del patrocinio universal al patrocinio particular}

Basándose en los evangelios de Mateo y Lucas, Millán de Poblete alude a la condición de theotokos de María ${ }^{4}$. En efecto, el evangelio de Mateo le sirve para recordar que el nacimiento de Jesús requería de esta virgen-madre preanunciada por los profetas. Ella entra, según la perspectiva de Mateo, en el misterioso plan de Dios para la salvación del pueblo y es insertada en la genealogía de Cristo por medio de una relación de promesacumplimiento y anunciada en el antiguo testamento (Lucchetti Bingemer, 2004, pp. 37-50). Millán de Poblete retoma estas consideraciones $y$, siguiendo la tradición, asocia la concepción de Jesús al cumplimiento de la profecía del libro de Isaías ${ }^{5}$, en la que se afirmaba que una virgen dará a luz al Mesías y a la lucha del profeta Elías contra el culto de Baal y los deseos de Atalía de exterminar la estirpe de David, de la cual proviene Jesús:

Porque el demonio por medio de este ídolo [Baal], instimulaba a Atalía, que quitase la vida a todos los de la ascendencia y generación de David, porque así se impidiese su descendencia y la generación de María Santísima y de Cristo señor nuestro, que a esta asestaba el demonio el tiro, para que ni se verifique la promesa de Dios de que una mujer había de ollar su cabeza en el primer instante de su ser [...]. Y así se ve, que lota la mira y el celo de Elías era el honor a la indemnidad de María Santísima... (Millán del Poblete, 1693, 8 v.)

Conjuntamente, el sacerdote novohispano retoma la valorización que Lucas hace tanto sobre la fe ejemplar como de la aceptación de la voluntad divina por parte de María (Lucas 1, 38). El evangelio de Lucas nos da a entender que además de la muerte, resurrección y vida pública de Jesucristo, es importante ver los orígenes de este, estrechamente relacionados a su madre (Román Martínez, 2009, pp. 33-42). En efecto, el Patrocinio de María Santísima, al igual que este evangelio, da especial importancia al significado teológico de la anunciación, evidenciando su connotación cristológica, pues sigue el esquema de la alianza llevada a cabo entre Dios e Israel en el Monte Sinaí: la gestación de Jesús ocurre a través de un elemento mediador y una respuesta de obedienciaservicio.

\footnotetext{
${ }^{4}$ Es decir. "He aquí, una virgen concebirá y dará a luz un hijo. Y llamarás su nombre Emanuel, que traducido es: Dios con nosotros" (Mateo 1, 23) y "A los seis meses, Dios envió al ángel Gabriel a Nazaret, pueblo de Galilea, a visitar a una joven virgen comprometida para casarse con un hombre que se llamaba José, descendiente de David. La virgen se llamaba María. El ángel se acercó a ella y le dijo: —iTe saludo, tú que has recibido el favor de Dios! El Señor está contigo. Ante estas palabras, María se perturbó, y se preguntaba qué podría significar este saludo. —No tengas miedo, María; Dios te ha concedido su favor —le dijo el ángel—. Quedarás encinta y darás a luz un hijo, y le pondrás por nombre Jesús. Él será un gran hombre, y lo llamarán Hijo del Altísimo. Dios el Señor le dará el trono de su padre David, y reinará sobre el pueblo de Jacob para siempre. Su reinado no tendrá fin. — ¿Cómo podrá suceder esto — le preguntó María al ángel—, puesto que soy virgen? —El Espíritu Santo vendrá sobre ti, y el poder del Altísimo te cubrirá con su sombra. Así que al santo niño que va a nacer lo llamarán Hijo de Dios. También tu parienta Elizabeth va a tener un hijo en su vejez; de hecho, la que decían que era estéril ya está en el sexto mes de embarazo. Porque para Dios no hay nada imposible. —Aquí tienes a la sierva del Señor — contestó María—. Que él haga conmigo como me has dicho" (Lucas 1, 26-38).

${ }^{5}$ La autora refiere a Isaías, 7, 14, texto que profetiza que de una virgen nascerá el Emmanuel o Mesías: "Por tanto, el Señor mismo os dará señal: He aquí que la virgen concebirá, y dará a luz un hijo, y llamará su nombre Emanuel".
} 
Millán de Poblete recuerda que María, madre del Dios encarnado, está relacionada con la redención de los individuos. Su gravidez representa una gestación universal-espiritual que le permite interceder por la salus eterna. Su maternidad origina la unión mística de todos los seres humanos con Cristo. En consecuencia, se debe tener total confianza en su intersección. Ella es una mediadora in Christo, por consiguiente, su veneración no se opone a la ortodoxia católico-romana (Aranda, 2018, p. 191). Sin embargo, para introducir la idea de que España posee un tratamiento especial, el novohispano recalca que María tiene otros hijos de su amor, a quienes ella reconoce como amantes hijos de su pecho. Estos son, en base a lo que el sermón desea transmitir, los españoles, quienes siempre han sido sus fieles.

Veámoslo en el evangelio, pues en el no solo elogia Marcela al virgíneo vientre, sino también sus castos puros pechos [...]. Porque en su vientre se simboliza un patrocinio universal, y común, más en los pechos se declara un patrocinio particular de un hijo especial de su amor [la monarquía española]. (Millán del Poblete, 1693, p. 3 v.)

Con esta diferencia entre el patrocinio universal para todos los humanos y el patrocinio particular para los españoles, el autor establece un binarismo basado en la noción de que esta monarquía universal está formada por una santa estirpe y por ciudadanos incorruptibles, que se oponen a los pueblos impíos. Por consiguiente, así como la anunciación sigue el esquema de la alianza entre Dios e Israel, el patrocinio mariano también corresponde al pacto o unión entre María y España. Este también obedece a leyes divinas y eternas. El autor explica los elementos determinantes de este vínculo por medio de una serie de factores que demuestran la santidad de la monarquía: la fusión del dogma cristiano de María con la imagen helénico-romana de un buen príncipe, la representación de España como un nuevo Israel y la función de los españoles como heraldos de la propagación del evangelio.

\subsection{De las columnas de Hércules al pilar de María: portadores y heraldos del mensaje salvífico}

En efecto, para demostrar la virtud de la monarquía, el autor alude al mito fundacional que hace de Hércules uno de los antepasados de los reyes de España, convirtiendo a la dinastía de los Habsburgo en una progenie heroica. Es decir, retoma elementos de la tradición mitológica española, en la que se consideraba que Hércules era su fundador mítico porque habría visitado la península y sus descendientes fundaron la casa de Navarra y de Borgoña (Gentilli, 2017, pp. 223-248). Conjuntamente, apunta que la fe de estos soberanos les hace ir más allá de las columnas de su ascendiente mitológico, quien al mismo tiempo representa el límite extremo de la falsa sabiduría y la imagen del buen príncipe marcado por la perfección moral. En consecuencia, retoma las creencias que a lo largo de los siglos XVI y XVII establecían paralelismos entre Carlos V y Hércules, dando a entender que el monarca español, al igual que su antepasado, había logrado dominar a los otros y a sí mismo, llegando incluso a superar al héroe del cual desciende:

¿Luego hubo de ser Hércules la adopción más que de otro? Claro está, no ven que fue Hércules tronco ilustrísimo de la serenísima casa de Austria, que desciende de 
aquel invicto héroe por su hijo Tusco, y era ya simbolizarle y apropiarle en aquellas fingidas sombras las verdades del patrocinio especial de María Santísima, que había de gozar la real augusta casa de Austria, y su católica monarquía puesta a los pechos de su amor. ¿Hay quien goce de esta prerrogativa por propia? ¿Hay quien pueda blasonar de hijo especial de María Santísima, sino es la monarquía católica criada de sus pechos, alimentada de su enseñanza y sustentada de sus favores? No hay que dudar, pues goza el título sin controversia. Pues véase ya en el virgíneo vientre el patrocinio universal de todos, pero en sus purísimos pechos el propio y particular que goza la católica monarquía católica en ellos simbolizado, pero ¿por qué es este todo el eje del sermón?. (Millán del Poblete, 1693, 4 r.)

La figura de Hércules permite que dentro del sermón se establezcan diversos niveles de pureza de la monarquía hispánica. España alcanza su apoteosis gracias a que los Austrias saben ir "plus ultra" tanto en el plano material como espiritual. Es indiscutible que Millán de Poblete sigue una tradición judaico-helenística-cristiana para hacer de España una monarquía amada por el ser divino, cuyo pueblo también fue elegido por sus méritos, como lo testimonian las iniciativas pías del visigodo Pelayo, de los reyes católicos, de Felipe II y toda la monarquía de los Austrias.

¿Cómo podemos esperar que goza el trono de luces nuestro católico Don Felipe el grande que, con tanto conato, esfuerzo y devoción, cuida de la indemnidad de aqueste primer instante debiéndole su declaración a su influjo? [...] Es imposible referir los continuos progresos, victorias y triunfos de la católica monarquía conseguidos a la protección de María Santísima desde el apretado lance de Covadonga, en donde se le apareció al señor rey don Pelayo, hasta nuestros tiempos. ¿Quién dio al santo rey don Fernando los yacimientos de Sevilla, sino María Santísima? [...] ¿Quién la conquista de este Nuevo Mundo, sino María Santísima en aquella milagrosa imagen tantas veces aparecida, en quien tenemos hoy todo nuestro remedio, nuestro asilo en las necesidades y en nuestras calamidades refugio? (Millán del Poblete, 1693, p. 8 v.)

El sacerdote realiza una interpretación doctrinal que resulta interesante para analizar la relación entre lo político y lo sacro en la Edad Moderna, principalmente durante el período en el que este texto fue escrito, es decir, a finales del siglo XVII. En esta época el monarca español era el enfermizo Carlos II, totalmente opuesto al hijo de Zeus y Alcmena según Mínguez (2013, p. 12), la delicada salud física e intelectual del monarca a lo largo de toda su vida obligó a los artistas de la corte a reforzar su débil imagen pública con apabullantes representaciones que compensasen las limitaciones de la presencia real-. El sacerdote novohispano aplica una estrategia de fortalecimiento de la monarquía que pasa por alto la condición de rex inutilis de Carlos II y sugiere que esta logra ir "plus ultra" de las columnas de Hércules gracias a la ayuda de la virgen del pilar, símbolo político-religioso de gran importancia para esta corona, pues es la única manifestación de María antes de su ascensión. Según la tradición religiosa española, durante su aparición sobre un pilar en Zaragoza, la virgen pidió que se construyera una iglesia, la cual permanecería hasta el fin de los tiempos. Su orden fue ejecutada — como antedicho en la salutación- por el apóstol Santiago y, gracias a la obediencia de este, se edificó el primer edificio bajo una advocación mariana (Serrano Martín, 2015, p. 37). 
...con lo que dijo María Santísima al apóstol Santiago, mandándole le fabricase un templo en España, como lo hizo en Zaragoza y fue el primero de la cristiandad apareciéndosele la señora, aún siendo viva, sobre una columna de jaspe, y la razón y motivo para que esto tuvo manifiesto diciendo: porque esta parte de España, dijo la soberana, me ha de ser muy devota, y tengo de ser muy reverenciada de los españoles, a los cuales ahora admito debajo de mi patrocinio y amparo... (Millán del Poblete, 1693, p. 6 v.)

El simbolismo del pilar es importante. Este representa la solidez del cristianismo. Su firmeza encarna la confianza en la protección de María, quien es el conducto entre el cielo y la tierra, es el eje de una construcción que liga entre sí distintos niveles. María y su santuario zaragozano son las primeras piedras del cristianismo, en torno a ellos crece el pueblo de Dios: España. Esta idea permite que el sermón se retome el motivo de representar a España como un nuevo Israel cristiano (Cruz Medina, 2019, p. 57). Su rey y sus súbditos son los responsables de la salvación del mundo, mediante un magisterio que les conduce a divulgar el plan de Dios. A España le corresponde combatir a los herejes con las armas espirituales de la iglesia y las temporales de los príncipes.

Así que en este reino católico se halla pura la fe, sin cizaña de herejía, ni espinas de infidelidad, pues esa es muy mía, no ha de tener otro patrocinio [...] ¿No es la monarquía española la católica por antonomasía? ¿No es la que ha conservado pura la semilla de la fe, sin permitir crecimientos de herejía? [...] Sí, pues claro que ha de gozar por muy propio de María Santísima el patrocinio a cuya jurisdicción se apropió la católica monarquía (Millán del Poblete, 1693, 6 r.).

En otras palabras, el favorecimiento mariano confía a España una universalidad sin fronteras. La obra enfatiza el carácter misional del rey y de sus vasallos, quienes están unidos a Dios por medio de María y, en consecuencia, tienen el deber esencial y constitutivo de hacer que los paganos de todos los rincones de la tierra puedan conocer el evangelio y encontrar el camino de la salvación.

Esta es la proposición convertible, que sembró la fe en un mundo, que era suyo y así es denotarnos, que este hombre no es otro que nuestro católico monarca, rey y señor, pues no hay otro que sea dueño de un mundo, si no es su majestad [que Dios lo guarde] que lo es de uno, y de dos, en quienes sembró y siembra su católico celo la fe promulgada y dilatada a sus expensas en uno y otro hemisferio. Solo el reino de España es quien conserva pura y limpia la fe, sin permitir crecimientos a la herejía [...] Pues por ello es muy particular el patrocinio y amor de María Santísima con la católica monarquía. (Millán del Poblete, 1693, p. 4 r.)

El prebendado lo menciona claramente, los españoles son "portadores" (p. 4 v.) del cristianismo. A través de sus acciones y palabras deben "sembrar la fe para su propagación" (p. 4 v.) Esta capacidad de portadores ya nos era preanunciada en la dedicatoria al conde de Galve, en la que no solo se aludía a la gran fe del conde, sino que se mencionaba como sus precedentes a Hernán Cortés y Cristóbal Colón. Si tomamos en cuenta que el nombre del almirante de la Mar Océana proviene del del latín Christophorus, y este del griego

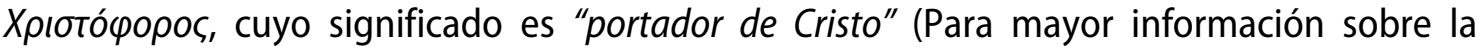
etimología del nombre Cristóbal, véase; Llompart Moragues, 1965), se puede colegir que 
tanto el nombre teofórico de este individuo como el apelativo teofórico del "católico monarca" son indicios que apuntalan que España debe servir para la difusión sacra del catolicismo y, al mismo tiempo, puede invocar la protección divina para sí. En otras palabras, la monarquía española tiene la tarea de adherir al kerigma cristiano. Este se basa tanto en la revelación inmediata como en la paradosis. España tiene la autoridad de ser kerux o heraldo de la salvación de Cristo. Es por ello que esta monarquía toma una posición abiertamente católica tanto en modo apologético, como teológico y principalmente kerigmático para cumplir su misión de constituir una comunión que acepta totalmente la doctrina cristiana.

\subsection{Revelaciones y predicaciones}

De hecho, las revelaciones divinas inmediatas presentes en el texto son principalmente dos: la aparición de la virgen del Pilar - a la cual ya se ha referido- y la conversión del soldado que clavó su lanza en el costado de Cristo. En Patrocinio de María Santísima ambos eventos son remitidos por Millán de Poblete como indicios del influjo divino. El apóstol Santiago y el soldado se convierten en representantes oficiales del catolicismo y ejercen una suerte de poder doctrinal. Santiago es el símbolo del sacerdocio ministerial por excelencia.

...pero el apóstol Tiago vino a España por elección de María Santísima, que lo eligió para esto aún vivo Cristo, nuestro señor, por ser prenda suya y sobrino suyo, por tener su sangre, sustituyendo en el sagrado apóstol sus veces y su patrocinio, que lo heredó y sacó de la sangre de María Santísima (Millán del Poblete, 1693, p. $6 \mathrm{v})$.

El soldado, en cambio, representa al primer cristiano-predicador español. Parece que el autor se basa en el texto atribuido a Flavio Lucio Dextro titulado Chronicon Omnimodae Historiae, obra en que intentaba presentar a España como cabeza de todo el occidente. Se piensa que dicho texto fue verdaderamente escrito por el jesuita Jerónimo Román de la Higuera. En lo que respecta al soldado que atravesó el costado de Cristo, existen dos versiones sobre el nombre del soldado que atravesó el costado de Cristo. Algunos lo refieren con el nombre de Longinos, otros como Cayo Opio. Según los evangelios apócrifos, este fue testigo de la colisión de las piedras y del eclipse de sol que tuvieron lugar después de la muerte de Jesús. Por estos milagros confesó la divinidad de Cristo, dejó la milicia y se agregó a los creyentes. Fue bautizado por San Pedro y, al regresar a la península, se convirtió en el primer predicador del cristianismo en España. Cristo había percibido la virtud de este centurión y sabía que su conversión — de la milicia a la lanza de la predicación- sería un aporte importante para el mundo (véase Tosaus Abadía, 1997). El autor afirma que aquel quien clava su lanza durante la crucifixión era español (1693, p. 5 r.) y pone en relieve que a este individuo le tocó la túnica inconsútil cuando sortearon las vestiduras de Cristo debido al hecho de que reconoció que Jesús era hijo de Dios y entendió la importancia salvífica de su muerte. El sacerdote novohispano hace de la túnica el emblema de la universalidad de la monarquía española, la cual debe esparcirse por el mundo y estar unida por una indisoluble unidad. 
Es la túnica abrigo, defensa y patrocinio del cuerpo y es obra de María Santísima. Eso es ya decirnos que es el patrocinio de María Santísima [...] y se echan suertes entre todos esos cuatro soldados, o entre esas cuatro partes del mundo, a quién ha de tocar por más propia la túnica o el patrocinio. ¿Y a quién le toca la suerte? A aquel soldado que [...] rompió el costado de Cristo señor nuestro [...] Este era español, en cuya boca se oyó para consuelo de María Santísima al pie de la cruz Vere filuis Dei erat iste. (Millán del Poblete, 1693, 4 v.-5 r.)

Es así que, por medio de Santiago y del soldado ganador de la túnica, el autor recuerda reiteradamente que a España le corresponde propagar - a los no cristianos, a los cristianos y a los descristianizados - la teología católica de un modo pastoral. Millán de Poblete insiste en mostrar la dimensión trascendental del kerigma y la manera cómo este es acreditado por las señales divinas que benefician a la monarquía universal española, cuya historia está marcada por milagros físicos y morales que ocurren gracias a sus heraldos o kerux, entre ellos pueden incluirse a los reyes, a los virreyes, a los conquistadores y, por supuesto, a los predicadores. La evangelización es uno de los deberes esenciales del patrocinio mariano.

\subsubsection{Predicador}

En efecto, la lectura de la obra sugiere que el patrocinio mariano está estrechamente relacionado con la predicación misionera o kerigmática llevada a cabo por la monarquía universal española, de su anuncio solemne del evangelio en los territorios ibéricos, periibéricos y en otras coronas cristianas. Por consiguiente, pareciera ser que, después de resaltar las razones por las cuales los españoles son un pueblo escogido por Dios, el sacerdote novohispano trata de poner un fin a la supuesta christomimesis gala y a las pretensiones que los franceses, quienes -apoyados en el título de Sa Majesté très chrétienne - tienden de pensar que su poder les había sido asegurado por la santísima providencia. Reivindicando sus supuestos derechos de Fils aîné de l'Église, estos justifican el papel de su monarca como «médiateur entre Dieu et les hommes», los franceses afirman su privilegio divino basándose en tres hechos: en la época de Clovis, los francos fueron el primer pueblo bárbaro que se convirtió al catolicismo, protegieron los estados pontificales en época de Pepín y Carlomagno y jugaron un papel muy especial en las cruzadas (véase el estudio de Myriam Yardeni, 1996). Millán de Poblete trata de desvirtuar la importancia de los franceses en la aceptación/propagación del cristianismo y afirma que:

...hasta el reino de Francia le debe a España la fe, pues San Dionisio de Areopagita, que fue primer obispo de París y apóstol de Francia, fue discípulo de Hieroteo, primer obispo de Atenas, y era español, a quien, el apóstol San Pablo encomendó la instrucción de San Dionisio y de toda Grecia [...] Pues si tanto siembra y dilata España la fe que mucho sea tan propio y tan suyo de María Santísima el patrocinio. Ojalá no se malogren nuestras tinieblas y el tener o enferma o muerta la fe con nuestras culpas. (Millán de Poblete, 1693, 5 v.) 
Hay dos particularidades que son muy significativas en este fragmento. La primera es que Millán de Poblete fusiona a Dionisio el Aeropagita ${ }^{6}$, Pseudo- Dionisio el Aeropagita ${ }^{7}$ y San Dionisio, apóstol de las Galias ${ }^{8}$ en una sola persona: el primer obispo de Lutecia, actual Paris. Millán de Poblete realiza esta amalgama gracias a la asimilación entre los Aeropagites y el sacerdote galo que, durante la Edad Media, hizo el abate Hilduin -véase el estudio de Théry (1923)- ${ }^{9}$. En efecto, del sofisma hilduiano proviene también la segunda particularidad del fragmento: el sermón relaciona al mítico personaje-amalgama con Hieroteo de Segovia ${ }^{10}$. Parece ser que Millán del Poblete se basa en el hecho de que el nombre de este aparece en De divinis nominibus atribuido al Pseudo-Dionisio de Aeropagita. En esta obra, Hieroteo es mencionado como el maestro del autor y se asevera que tenía un lugar especial en la iglesia, pues era guiado por las luces del eterno y soberano espíritu (Cattaneo, 2019, pp. 295-297). En Patrocinio de María Santísima, Millán de Poblete considera que la relación maestro-discípulo entre Hieroteo y Dionisio es esencial y permite retratar la profundidad del empeño evangelizador español. Las enseñanzas del predicador Hioroteo han servido para que el obispo de Lutecia haga progresar espiritualmente a la monarquía francesa. Por consiguiente, es un modelo de cómo España expande el catolicismo. En efecto, no es superfluo que el autor mencione a Hieroteo. Este le permite aludir a la importancia del predicador, del individuo por medio del cual se expresan las cuestiones de carácter divino. Es un hombre de la iglesia que permite cuidar el rebaño de Cristo y predicar la palabra de la fe. Millán de Poblete, al igual que Hieroteo, es un heraldo o kerux que lleva un mensaje con la autoridad de la palabra de Cristo y el patrocinio de María. Este novohispano, como lo afirma Florencia en su parecer, es la prueba de que no se puede propagar el evangelio sin el predicador. Sin ellos, la monarquía no puede ser portadora del mensaje de Cristo, no puede haber la paradosis. Son los predicadores quienes explican el sentido de la fe cristiana. En efecto, la celebración del patrocinio de María es una ocasión precisa para explicar la importancia del munus docendi y la contribución de este al desarrollo de una consciencia dogmática que va más allá de los límites espacio-temporales y permite la expansión de la monarquía universal española. Es indudable que en Patrocinio de María hay un juego de autorrepresentación o self-fashioning que se presenta por medio de la evaluación y exaltación de la función del predicador. El prebendado realiza un extraordinario juego dinámico con los códigos monárquicos y religiosos, presentándose como un súbdito ejemplar e irremplazable de España. Esto sucede de manera muy natural, pues por medio del soldado ganador de la túnica y de Hieroteo, convertidos en arquetipos del predicador español, Millán de Poblete se promociona a sí mismo. Esta autopromoción es percibida claramente por los censores y por el lector.

\footnotetext{
${ }^{6}$ Según los hechos de los apóstoles, era un ateniense que formaba parte de los filósofos que escuchaban la predicación de San Pablo y es considerado el primer obispo de Atenas.

${ }^{7}$ Es el autor de una serie de tratados cristianos de teología mística que firmó con el nombre del ya mencionado griego, por ello se lo conoce como el pseudo-Dionisio el Aeropagita.

${ }^{8}$ San Dionisio o Saint-Denis, santo tutelar y primer obispo de Lutecia, actual París.

${ }^{9}$ Este abate deseaba hacer una transferencia simbólica de Grecia a Francia, convirtiendo a Lutecia en la Atenas del cristianismo.

${ }^{10}$ Hieroteo de Atenas o de Segovia. Griego, supuestamente el primer obispo de Segovia. Considerado un santo, predicador y místico. Su personalidad histórica nunca se ha podido demostrar.
} 


\section{Conclusiones}

En este estudio se ha presentado una imagen panorámica y un análisis filológico del contenido textual y paratextual de Patrocinio de María Santísima, sermón escrito y predicado por Juan Millán de Poblete en 1693. Del examen de este texto se puede notar que, si bien la mariología ocupa un lugar primordial en el texto, esta se combina con motivos que tratan de realzar la importancia de la monarquía española, de sus autoridades y de sus súbditos. En efecto, en el texto se trata de otorgar a España una misión salvífica, debido a que este es el nuevo pueblo elegido por Dios y tienen la función de portadores del cristianismo. El sermón encaja perfectamente en la homilética de su época, pues están presentes los temas comunes de la contrarreforma: el theotokos, la función mediadora de María entre Dios y los hombres, su papel de auxiliadora de los cristianos. Conjuntamente, logra relacionar las cuestiones teológicas con los asuntos imperiales.

En consecuencia, se puede concluir que Patrocinio de María Santísima constituye un buen un ejemplo de la mariología política en Nueva España. En efecto, en esta obra la mariología se asocia a la ideología imperial por medio de diferentes señales a las que se alude tanto en el texto como en el paratexto. La conversión del soldado que ganó la túnica de Cristo, la aparición de la virgen del Pilar en Zaragoza y la coincidencia de las iniciativas de conquista/descubrimiento con fechas religiosas marianas son parte de las manifestaciones que muestran que España es el nuevo Israel. De hecho, Patrocinio de María Santísima trata de convencer que la verdadera translatio consiste en el hecho de que los españoles son el nuevo pueblo elegido por Dios. Para demostrarlo el sacerdote usa la imagen del optimus prínceps tanto en el texto como en el paratexto. Por consiguiente, en el sermón, el monarca español es idealmente representado como alguien que logra ir "plus ultra" de los límites impuestos por Hércules. En el paratexto es representado con la imagen de Gaspar de la Cerda asociado al cetro, símbolo del poder soberano y del sacerdocio. Conjuntamente, el sermón transmite la idea de que no hay optimus prínceps sin optimus civis. Millán de Poblete presenta una serie de individuos que encarnan la imagen del súbdito ideal: los píos conquistadores; el bachiller Andrés Ortiz de Cobarrubias, fautor del sermón, el soldado ganador de la túnica y Hieroteo. Los dos últimos constituyen una suerte de autorrepresentación de Millán de Poblete, pues al igual que él, desempeñan el papel de los predicadores, por medio de los cuales se expresan las cuestiones de carácter divino. Estos tienen la función de ser heraldos o kerux de la palabra de Cristo y del patrocinio de María, el cual es representado, entre muchos motivos, por el pilar en el que se aparece María en Zaragoza. Este representa la solidez del cristianismo en la monarquía hispánica, la cual permite difusión sacra del catolicismo, como bien lo revela el lugar del frontispicio: la catedral de la ciudad imperial de México. Patrocinio de María Santísima logra transmitir la idea de que el verdadero puente transatlántico que une la Península Ibérica con sus territorios ultramarinos es la fe. En suma, después de haber analizado el texto se puede concluir que Patrocinio de María Santísima es una obra que una importante para el estudio de la tradición homilética en Nueva España, pues nos permite ver la manera cómo la historia doctrinal y literaria de la corona se adapta/transmite en este virreinato. Millán de Poblete se apropia de la teología imperial, retomando motivos ya presentes en modelos clásicos y sermones célebres, pero al mismo tiempo se distancia de estos por medio de su propia 
concepción de la monarquía hispánica como una totalidad, que va de la primera iglesia dedicada a María en Zaragoza a la catedral del virreinato de Nueva España. En este sermón, el autor realiza una presentación parcializada y condescendiente de los motivos contrarreformistas y promonarquía española de la época, que lo conduce a escribir un texto que se articula con la mariología política que justifica el dominio de los Habsburgo en los territorios ultramarinos y el mesianismo hacia los pueblos amerindios — considerados paganos- Lógicamente, a pesar de que el texto adhiere perfectamente a la lógica postridentina, es evidente que Poblete deja de lado muchos aspectos complejos ya tratados por las diversas teorías jurídico-ético-morales del iusnaturalismo, pues la obra manipula la imagen de María evadiendo las nociones de derecho natural de gentes. En consecuencia, Juan Millán de Poblete asume su papel de mariologista imperial, la apología a la virgen tiene una función doble: alabar los pilares del catolicismo, encomiar a la monarquía. El texto sigue las líneas doctrinales de la estructuración de la iglesia como una monarquía y de la monarquía española como una guardiana de la fe, fusionando el supuesto empeño espiritual y orientación autoritaria de ambas instituciones en la temprana modernidad.

\section{Agradecimientos}

Tuve la oportunidad de consultar la editio prínceps durante mis investigaciones en la New York Public Library. Agradezco de manera muy especial a Ben Heller, profesor asociado de la University of Notre Dame, por haberme sugerido que solicitara una Small Grant (Department of Romance Languages), la cual me permitió cubrir algunos gastos en Nueva York. Conjuntamente, doy gracias a las personas que me asistieron durante mis investigaciones en la "Rare Book Division" de la ya mencionada biblioteca, especialmente al bibliotecario Kyle Triplett y a sus asistentes Ted Teodoro, John Cordovez y Nasima Hassam.

\section{Referencias Bibliográficas}

Aranda, A. (2018). La «mediación materna» de María en el diálogo ecuménico. Estudios marianos, (84), 191-214. https://bit.ly/3bTZWfE

Arnold, J. J. (2014). Theoderic and the Roman imperial restoration. Cambridge University Press. https://doi.org/10.1017/CBO9781107294271

Bengoechea, I. (1985). "Maria, Mater Nostri Capitis"(San Isidoro de Sevilla). Marian Library Studies, 17(1), 255-263. https://bit.ly/2Zqpfkq

Cattaneo, G. (2019). S. Lilla, Dionysii Areopagitae De divinis nominibus, ed. cur.C. Moreschini, Edizioni dell'Orso, Alessandria 2018, pp. LXXX-174. Prometheus, 45 (1): 295-297. https://doi.org/10.14601/prometheus-25805

Cerbo, A. (2018). Forme e strategie di colloquio nella poesia di Tommaso Campanella. En B. Bonhomme, A. Cerbo y J. Rieu (Dir.), La poésie comme entretien= La poesia come colloquio (pp. 81-87). Paris: L'Harmattan 
Campos y Fernández de Sevilla, F. J. (2012). La Virgen del Patrocinio y el Monasterio del Escorial. En Advocaciones Marianas de Gloria (pp. 699-732). San Lorenzo del Escorial: Ediciones Escurialenses. https://bit.ly/32o4rMz

Cruz Medina, J. P. (2019). Imágenes para sacralizar, controlar y someter. La pintura y el discurso matrimonial tridentino en el Nuevo Reino de Granada. Siglo XVII. Anuario de Historia Regional y de las Fronteras, 24(1), 57-82. http://doi.org/10.18273/revanu.v24n12019003

De Fiores, S. (2005). María sintesi di valori: storia culturale della mariologia. Cinisello Balsamo: Edizioni Paoline.

De la Torre García, E. (2000) Los Austrias y el poder: la imagen en el siglo XVII. Historia y comunicación social, (5), 13-29. https://bit.ly/3k0UB9a

García-Saúco Beléndez, L. G. (1986). Un aspecto de la sociedad del Barroco del XVII: la devoción a la Inmaculada Concepción en Albacete. Al-Basit (Albacete. Internet), 12(18), 33-45. https://bit.ly/3mfdbwh

Gentilli, L. (2017). Hércules, icono y máscara de soberanos en la corte de los últimos Austrias. En L. Gentilli y R. Londero (Eds.). Sátira y encomiástica en las artes y letras del siglo XVII español (pp. 223-248). Madrid: Visor.

Guerrero Cano, M. M. (1983). El Patronato de Granada y el de Indias: algunos de sus aspectos. En B. Torres Ramírez y J. J. Hernández Palomo (Coords.), Andalucía y América en el siglo XVI (Vol. 1, pp. 69-90). Sevilla: Escuela de estudios hispano-americanos. https://bit.ly/3c14fWH

Jiménez Sureda, M. (2014). La transformación de ciudades en conceptos en el mundo medieval y en el mundo moderno: Roma y Troya. Intus-Legere historia (En línea), 8 (2), 87128. https://bit.ly/3kcary6

Llompart Moragues, G. (1965). San Cristóbal, como abogado popular de la peregrinación medieval. Revista de dialectología y tradiciones populares, 21(3), 293-313.

Lucchetti Bingemer, M. C. (2004). María y su dimensión místico profética. Revista CLAR, 42(1), 37-50. https://bit.ly/3kaEkP3

Merrim, S. (2012). The spectacular city, Mexico, and colonial Hispanic literary culture. Austin, TX: University of Texas Press.

Milán, F. (2010). Pablo $M^{a}$ Edo, El lenguaje de las vestiduras en el cuarto evangelio, Pamplona: Eunsa («Colección Teológica»), 2009, 262 pp., 15,5 x 24, ISBN 978-84-313-2302-9. Scripta theologica, 42 (1), 242-243. https://bit.ly/2FpWSvL

Martínez Millán, J. (2015). Evolución política y religiosa en la monarquía hispana durante el siglo XVII. Carthaginensia, 31(59/60), 215-250. https://bit.ly/32mU63h 
Olivera, B. (2018). Sermones sobre el Cantar de los cantares de san Bernardo de Claraval. Cuadernos Monásticos, (205), 144-163. https://bit.ly/2DYaAWq

Parker, G. (2001). The world is not enough: the imperial vision of Philip II of Spain. Waco, TX: Baylor University Press.

Pastori Ramos, A. (2010). La Segunda Cruzada y su fracaso en De Consideratione ad Eugenium Papam de Bernardo de Claraval. Mirabilia (Online), (10), 70-84. https://bit.ly/2Zwr9jz

Román Martínez, M. C. (2009). María, modelo del discípulo, según Lucas. Reseña Bíblica, (61), 33-42. https://bit.ly/3khMci3

Serrano Martín, E. (2015). Milagros, devoción y política a propósito de la virgen del Pilar en la edad moderna. e-Spania (En ligne). (21). https://doi.org/10.4000/e-spania.24814

Théry, G. (1923). Hilduin et la première traduction des écrits du Pseudo-Denis. Revue d'histoire de l'Église de France, 9(42), 23-39. https://doi.org/10.3406/rhef.1923.2260

Tosaus Abadía, J. P. (1997). Longinos: de la Biblia al Cantar de Mio Cid. En A. Borrell Viader, A. Puig i Tàrrech y $A$ José o la construcción de la fraternidad: lectura narrativa antropológica de la Fuente (Coords.), La Bíblia i el Mediterrani (Vol. 2, pp. 87-100). Barcelona: Associació Bíblica de Catalunya.

Turpo Chaparro, J. (2014). Sombras y realidades: el ungimiento de Aarón, sus hijos y el santuario y su cumplimiento en el Nuevo Testamento. Revista Hermenêutica (Cachoeira. Online), 14(2), 47-76. https://bit.ly/2DYI1t4

Úzquiza Ruiz, T. (2012). Símbolos en el arte cristiano. Breve diccionario ilustrado. Burgos: Sembrar.

Wénin, A. (2011). de Génesis 37-50 (J. Gómez, Trad.). Bogotá: San Pablo.

Yardeni, M. (1996). Le christianisme de Clovis aux XVI e et XVII e siècles. Bibliothèque de I'École des chartes, 154(1), 153-172. https://bit.ly/3kctxnM

Zuanazzi, I. (2018). La mitezza quale paradigma della funzione di governo nella Chiesa. lus Ecclesiae, 30(1), 79-99. https://doi.org/10.19272/201808601005

\section{Para citar este artículo bajo Norma APA 7a ed. \\ Taiano Campoverde, L. (2020). Virgen, monarquía y predicador \\ en Patrocinio de María Santísima de Juan Millán de Poblete. Cuadernos de teología - Universidad Católica del Norte (En línea), \\ 12, e4219, https://doi.org/10.22199/issn.0719-8175-2020-0003}

Copyright del articulo: (22020 Leonor Taiano

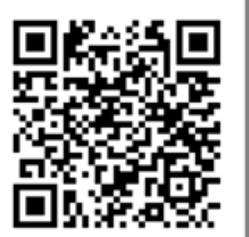

DOI

\footnotetext{
Este es un artículo de acceso abierto, bajo licencia Creative Commons BY 4.0.
} 